* Artigo Original

\title{
Avaliação de sites de saúde em questão: a Aids nos sites brasileiros de Organizações Não Governamentais (ONG) de Lésbicas, Gays, Bissexuais, Travestis e Transexuais (LGBT)
}

\author{
André de Faria Pereira Neto \\ Fundação Oswaldo Cruz. Professor e Pesquisador da Escola Nacional de Saúde Pública da \\ Fundação Oswaldo Cruz. \\ apereira@fiocruz.br
}

\section{Elizabeth Moreira dos Santos}

Fundação Oswaldo Cruz. Professora e Pesquisadora da Escola Nacional de Saúde Pública da Fundação Oswaldo Cruz.

bmoreira@ensp.fiocruz.br

\section{Marly Marques da Cruz}

Professora e Pesquisadora da Escola Nacional de Saúde Pública da Fundação Oswaldo Cruz. mnavarro@fiocruz.br

\section{Raquel Maria Cardoso Torres}

Mestranda de Saúde Pública da Escola Nacional de Saúde Pública da Fundação Oswaldo Cruz. raquelmct@gmail.com

DOI: $10.3395 /$ reciis.v7i1.588pt

\section{Resumo}

OBJETIVO. Apresentar uma proposta metodológica de avaliação da qualidade da informação disponível em sites de saúde, com seus respectivos indicadores e pesos e aplicar esta ferramenta metodológica na avaliação das informações sobre a HIV/AIDS disponíveis em sites de Organizações Não Governamentais (ONG) que defendem os direitos de Lésbicas, Gays, Bissexuais, Travestis e Transexuais (LGBT) de oito estados do Brasil. METODOLOGIA. Combina três dimensões na avaliação das informações disponíveis em sites de saúde: o conteúdo, a usabilidade e a legibilidade. Cada uma destas dimensões é subdividida em indicadores que recebem pesos. Esta avaliação foi feita pelos autores em Novembro de 2010. Foram utilizados três critérios, a saber, de conteúdo, de usabilidade e de legibilidade. Cada um deles é composto por uma série de indicadores. A pontuação obtida por cada site em cada um dos indicadores é apresentada de forma clara. Neste sentido este artigo apresenta uma contribuição para o tema. RESULTADOS. Nenhum dos sites de Organizações Não Governamentais de LGBT analisados neste artigo apresenta informações sobre HIV/AIDS que atendam minimamente aos critérios, indicadores e pesos apresentados na metodologia deste trabalho. Este estudo demonstra que a avaliação da qualidade da informação na Internet é imprescindível.

Palavras-Chave: Avaliação em Saúde; Webcasts como Assunto; Informação de Saúde ao Consumidor; Síndrome de Imunodeficiência Adquirida (SIDA). 


\section{Introdução}

O mundo presenciou, nos últimos anos, uma intensa e radical transformação tecnológica que tem, entre outras conseqüências, proporcionado crescimento do acesso à informação através da Internet. Há mais informação disponível e ela é, cada vez mais, fácil e rapidamente acessível[1]'[2]. Na Web as fontes de informação disponíveis são infinitas e as possibilidades de interatividade entre os indivíduos estão extremamente ampliadas. Nos tempos atuais, não há nada semelhante à Internet como meio de difusão e produção de informação[3].

Em um contexto marcado pelo aumento da presença desta tecnologia no cotidiano do cidadão, a saúde desponta como uma das áreas onde há um crescente volume de informações. Todos os dias novos sites sobre saúde e doença são disponibilizados oferecendo informações a profissionais e usuários, até então, inacessíveis. No Brasil pesquisa recente indica que 39\% dos internautas acessam a Internet procurando informações ou serviços relacionados com a saúde[4]. O impacto das informações disponíveis na Internet na prevenção e na promoção da saúde de milhares de pessoas do planeta parece indiscutível[5],[6].

A Internet possui uma característica que a singulariza dos demais veículos de comunicação: na Web os cidadãos que têm acesso à internet e expertise com as ferramentas da web têm condições de produzir informação. Os tradicionais veículos de comunicação estão perdendo o monopólio da produção de informação. Muitos sites de saúde são elaborados e mantidos por empresários, profissionais, associações, empresas e por organizações (não) governamentais, universitárias e de pesquisa. Esse fato, que pode ser interpretado como uma virtude, gera um problema: nenhuma das informações oferecidas por estas instituições ou pessoas sofre qualquer tipo de regulação ou avaliação em relação ao conteúdo disponibilizado. Esta característica faz com que, muitas vezes, seja oferecida uma informação incompleta, contraditória, incorreta, incompreensível, desatualizada ou até fraudulenta. O usuário e o profissional têm dificuldade de discernir qual página na web deve merecer crédito e qual deve ser ignorada ou rejeitada. O acesso a este tipo de informação pode colocar em risco a saúde do cidadão e de sua família[7]. Por esta razão, a questão da avaliação da qualidade da informação em saúde disponibilizada pela Internet tem se tornado um tema fundamental em diferentes campos do conhecimento[8],[9],[10].

O objetivo deste artigo é apresentar uma metodologia de avaliação da qualidade das informações disponíveis em sites de saúde. Ele visa discutir os achados relativos à sua aplicação a sites de Organizações Não Governamentais (ONG) que defendem os direitos de Lésbicas, Gays, Bissexuais, Travestis e Transexuais (LGBT) em oito estados do Brasil, particularmente quanto a informações sobre o HIV/AIDS. Esta escolha se justifica pelo papel proeminente que estas ONGs vêm desempenhando no Brasil na defesa dos direitos de acesso ao tratamento da AIDS e aos medicamentos antirretrovirais oferecidos pelo Sistema Único de Saúde. Esta avaliação foi feita pelos autores em Novembro de 2010. Não houve necessidade de submissão ao Comitê de Ética em Pesquisa, pois as informações avaliadas são de domínio público. 


\section{Procedimento Metodológico}

A preocupação com a avaliação das informações sobre saúde disponíveis na Internet tem pouco mais de dez anos ${ }^{11}$. Esta constatação foi fruto da busca na base brasileira do scielo, em Maio de 2010. Na oportunidade a estratégia foi utilizar a palavra chave internet no campo assunto. Diante dos trinta e seis títulos encontrados foi feita uma seleção daqueles que tivessem sido referenciados com a palavra avaliação. Assim foram apenas nove artigos tratam da avaliação de sites de saúde[11],[12],[13],[14],[15],[16],[17],[18],[19]. Esta realidade sugere que seja ainda incipiente a produção nacional neste campo. Em termos internacionais, entretanto, a realidade é outra. Esta preocupação pode ser percebida no British Medical Journal e no Journal of the American Medical Association desde 1997 [20],[21],[22] . Eysenbach e colaboradores[23] publicaram em 2002 os resultados de uma ampla Revisão Sistemática, analisando 79 artigos sobre o tema apresentando 86 critérios diferentes para a avaliação de sites de saúde. Realizando um esforço de síntese, Eysenbach e colaboradores ${ }^{23}$ reuniram estes critérios em cinco grupos que reúnem alguns indicadores, a saber: Técnico que se refere à maneira de obtenção da informação; Acurácia - sobre o grau de concordância existente entre a informação disponibilizada e o conhecimento aceito e reconhecido pela ciência sobre aquele assunto; Abrangência - que verifica o grau de cobertura da informação; Desing - que avalia os aspectos visuais do site e Legibilidade - sobre o nível de compreensão do texto.

Reunimos os três primeiros critérios apresentados nesta revisão sistemática em um mesmo conjunto que denominados conteúdo. Ele inclui a maneira com que a informação e sua fonte são apresentadas. Neste caso, o site deve apresentar o nome e demais dados de seu proprietário e do responsável pelas informações disponibilizadas assim como suas referências. Esta preocupação também pode ser identificada no "Manual de Princípios Éticos para Sites de Medicina e Saúde" do Conselho Regional de Medicina do Estado de São Paulo (CREMESP)[24]. Alem disso, deve ser verificado se o site em questão tem interesses financeiros ou patrocínio comercial. Deve ser verificado ainda o grau de concordância da informação oferecida no site com a melhor evidência geralmente aceita pela prática médica, ou seja, deve ser observada sua acurácia ${ }^{23}$. Para tanto, deve ser solicitada avaliação de especialistas no tema[25]. Finalmente deve ser verificado em que medida o site analisado menciona os elementos-chave daquele tema ou problema de saúde como o diagnóstico, a prevenção, as possibilidades de tratamento e suas possíveis complicações[26].

Desing passou a ser denominado neste trabalho de usabilidade. A expressão legibilidade utilizada por Eysenbach e colaboradores ${ }^{23}$ foi mantida.

A primeira contribuição deste estudo reside na apresentação de três e não de cinco critérios para avaliação. Nossa proposta metodológica de avaliação está estruturada, portanto, em torno de três critérios. Cada um deles é composto por seus respectivos indicadores, cada qual com um peso específico, compondo um checklist. Os indicadores foram resgatados nos estudos avaliados por Eysenbach e colaboradores ${ }^{23}$. Estes valores somados permitem que seja criado um ranking entre os sites e possibilita que usuários e responsáveis identifiquem os pontos fortes e fracos de cada site. A pontuação foi arbitrada de modo a fazer com que os três indicadores recebessem a mesma pontuação máxima. Com isso defendemos a idéia que a 
informação disponível em um site de saúde deve contemplar os três aspectos presentes em cada um dos indicadores.

No critério de conteúdo enumeramos vinte indicadores de avaliação de qualidade de informação de sites de saúde. Eles foram retirados do estudo empreendido por Eysenbach e colaboradores $^{23}$. Os três primeiros indicadores devem receber maior destaque, pois verificam a autoria e a responsabilidade pelo site: um aspecto que boa parte da literatura internacional analisada por Eysenbach e colaboradores ${ }^{23}$ admite que não possa faltar. Um site de saúde deve deixar explícito o nome de seu responsável seguido de suas credenciais - formação, títulos e/ou ações - que abonem as responsabilidades inerentes à sua função. No caso específico deste estudo, foi considerado o responsável pela organização não governamental que é responsável pelo site. Da mesma forma, e com o mesmo grau de importância, deve constar a empresa ou organização patrocinadora ou parceira do site. Os cinco demais indicadores devem receber peso menor, apesar de tratarem de dois aspectos fundamentais: a fonte da informação e a data da atualização da informação. Estes indicadores são relevantes, mas, numa escala de prioridade, são menos importantes que os três primeiros. Um site de saúde tem que deixar claro onde obteve a informação sobre aquele assunto e quando ela foi disponibilizada. Deve ser observado se existe uma referencia formal relacionada com a sua atualização. Estes dois indicadores conferem credibilidade à informação oferecida, valorizandose tanto a informação oferecida por um experto como aquela recuperada em manuais e livros. Deve-se verificar ainda quando foi realizada a última atualização. Se ela tiver sido feita nos últimos 30 dias indica que os responsáveis pelo site têm esta preocupação com a gestão deste serviço de informação. Este aspecto é relevante, pois o conhecimento em saúde atualiza-se, muitas vezes, em um curto espaço de tempo. Trinta dias foi um prazo considerado por nós como razoável para um site ser atualizado. Os doze itens seguintes têm peso um, pois comparados com os anteriores nos parecem menos determinantes. O primeiro verifica se está explícito a que público o site se dirige[27]. Os oito indicadores seguintes tratam da acurácia e a cobertura (scope) da informação relacionando o diagnóstico, a prevenção, o tratamento e suas conseqüências. As duas seguintes buscam verificar a existência de anúncios, especialmente os de medicamentos e a última averigua se há alguma menção ao momento no qual o médico deve ser chamado. Assim constitui-se uma hierarquia entre os indicadores dentro de cada critério. Uma hierarquia que visa classificar ou ordenação os indicadores em função de sua relevância, seguindo as conclusões dos estudos analisados por Eysenbach e colaboradores $^{23}$.

Este artigo apresenta o quadro de indicadores de avaliação de conteúdo de sites de saúde organizado da seguinte forma:

Quadro I. Indicadores de avaliação de conteúdo de Site de Saúde

\begin{tabular}{|l|l|l|l|l|l|}
\hline Indicador & $\mathbf{1 0}$ pts & $\mathbf{5}$ pts & Zero & $\mathbf{P}$ & Total \\
\hline Consta o responsável pelo Site/ONG? & Sim & & Não & 3 & 30 \\
\hline $\begin{array}{l}\text { Constam as Credenciais do } \\
\text { Responsável? }\end{array}$ & Sim & Em Parte & Não & 3 & 30 \\
\hline Consta o Patrocinador/Parceiro do & Sim & & Não & 3 & 30 \\
\hline
\end{tabular}




\begin{tabular}{|c|c|c|c|c|c|}
\hline Indicador & 10 pts & 5 pts & Zero & $\mathbf{P}$ & Total \\
\hline \multicolumn{6}{|l|}{ Site? } \\
\hline Consta a data da Criação do Site? & Sim & & Não & 2 & 20 \\
\hline Consta a data da última atualização? & Sim & & Não & 2 & 20 \\
\hline $\begin{array}{l}\text { Quando foi feita última atualização? } \\
\text { Há... }\end{array}$ & 30 dias & 60 dias & $\begin{array}{l}90 \\
\text { dias }\end{array}$ & 1 & 10 \\
\hline $\begin{array}{l}\text { Consta o Público a que o site se } \\
\text { dirige? }\end{array}$ & Sim & & Não & 1 & 10 \\
\hline $\begin{array}{l}\text { Consta Fonte de Informação na Página } \\
\text { da Doença? }\end{array}$ & Sim & & Não & 2 & 20 \\
\hline $\begin{array}{l}\text { Que Tipo de Fonte de Informação foi } \\
\text { utilizada? }\end{array}$ & Experto & Livro & $\begin{array}{l}\text { Pessoa } \\
\text { I }\end{array}$ & 2 & 20 \\
\hline $\begin{array}{l}\text { Consta como fazer o exame } \\
\text { Diagnóstico da Doença? }\end{array}$ & Sim & & Não & 1 & 10 \\
\hline $\begin{array}{l}\text { Os exames Diagnósticos estão de } \\
\text { acordo com a ciência? }\end{array}$ & Sim & Em Parte & Não & 1 & 10 \\
\hline Consta como se Prevenir da Doença? & Sim & Em Parte & Não & 1 & 10 \\
\hline $\begin{array}{l}\text { A prevenção está de acordo com a } \\
\text { ciência? }\end{array}$ & Sim & Em Parte & Não & 1 & 10 \\
\hline O Tratamento é preconizado? & Sim & & Não & 1 & 10 \\
\hline $\begin{array}{l}\text { O Tratamento está de acordo com a } \\
\text { ciência? }\end{array}$ & Sim & Em Parte & Não & 1 & 10 \\
\hline $\begin{array}{l}\text { Constam as conseqüências do } \\
\text { Tratamento? }\end{array}$ & Sim & Em Parte & Não & 1 & 10 \\
\hline $\begin{array}{l}\text { As conseqüências estão de acordo } \\
\text { com a ciência? }\end{array}$ & Sim & Em Parte & Não & 1 & 10 \\
\hline Constam anúncios? & Não & Até 5 & + de 5 & 1 & 10 \\
\hline Constam anúncios de medicamentos? & Não & & Sim & 1 & 10 \\
\hline $\begin{array}{l}\text { Consta quando o médico deve ser } \\
\text { chamado? }\end{array}$ & Sim & & Não & 1 & 10 \\
\hline Total & & & & & 300 \\
\hline
\end{tabular}

O segundo critério se refere à usabilidade do usuário no site. Usabilidade é definida como o fator que assegura que os produtos são fáceis de usar, eficientes e agradáveis - da perspectiva do usuário. Implica em otimizar as interações estabelecidas pelas pessoas com 
produtos interativos (web, software...), de modo a permitir que realizem suas atividades no trabalho, em casa, em qualquer lugar. Ela interfere no acesso à internet de pessoas com pouca experiência, baixa escolaridade e diferente faixa etária[28]. O sistema informatizado em rede, em última instância, é um artefato que media a comunicação entre uma instituição (pública, privada, ou até mesmo indivíduos) e um usuário interessado no serviço oferecido. Esta comunicação não presencial pressupõe uma troca dinâmica de dados, a utilização de signos comuns e a capacidade de antecipação de necessidades e procedimentos. A navegação deve ser mais intuitiva, no sentido de ser automática, ou processada inconscientemente e deve solicitar pouco esforço cognitivo - facilitando a ação e reduzindo a probabilidade de erros ${ }^{28}$.

Ao avaliar a usabilidade de um site esta metodologia pretende verificar a capacidade de um determinado site de permitir que o usuário circule com facilidade e rapidez em seu interior e nos links que disponibiliza. Eles devem ser interessantes, pertinentes e, sobretudo, agradáveis. Um site tem uma navegação fácil se o usuário consegue passar, sem dificuldade e com rapidez, de uma página para outra, voltando a anterior. Este critério atesta ainda se a informação é ou não facilmente encontrada na homepage. As imagens, diagramas e fotografias sobre a doença devem ter a referência de sua fonte, ter qualidade visual e ajudar a esclarecer a informação oferecida, mantendo com o texto uma relação complementar. É fundamental que existam os mecanismos de busca e navegação internos que promovam a interatividade entre os usuários tais como, twitter, facebook e entre estes e os gestores do site como o e-mail, o endereço para correspondência, telefone ou fax do responsável pelo site ou entidade que lhe dá suporte. As estatísticas de acesso evidenciam a popularidade do site[29].

Seguindo o modelo anterior, construímos, em relação à usabilidade outro quadro contendo vinte indicadores (Quadro II). Os três primeiros receberam a maior pontuação, pois são considerados os mais importantes. Eles se referem aos aspectos mais relevantes dentro deste critério. Em primeiro lugar, cabe verificar se existe um "Menu Principal". É através dele que o usuário terá uma idéia geral e abrangente da estrutura do site. A inexistência de um "Menu Principal" inviabiliza os primeiros passos para a navegação em qualquer site. Em segundo lugar cabe verificar, analisando a página de abertura se o avaliador considera o site é agradável visualmente. Em terceiro lugar, vale constatar se a passagem de uma página para outra, dentro do site é rápida. Estabelecemos 5 segundos o tempo médio para o site mostrar a informação depois de solicitada. Este pode ser considerado um tempo tolerável de espera na navegação na Web nos dias de hoje. Os seis indicadores seguintes receberam menos pontos. Eles se referem a aspectos igualmente importantes, apesar de não serem decisivos como os três anteriores. Estes pesos têm a finalidade de fazer com que os três critérios, apesar de terem um número diferente de indicadores possam alcançar ao final a mesma pontuação máxima. A comunicação entre sites, entre usuários e entre usuários e gestores do site adquire neste contexto papel fundamental. Um veículo de comunicação digital não deve prescindir destas dimensões de interatividade. Pelo contrário, deve estimulá-las. Estão incluídos ainda no segundo grupo de indicadores a existência de imagens sobre a doença e as estatísticas de uso do site. O primeiro pode facilitar a compreensão do texto escrito enquanto o segundo oferece uma dimensão da assiduidade de vistas ao site. Os onze indicadores seguintes são desdobramentos dos nove primeiros. Em relação ao "Menu Principal" é importante que existam menus secundários, um Mapa do Site e mecanismos de busca interna. Estes são recursos que facilitam a usabilidade e auxiliam o usuário a encontrar aquilo que deseja. Em termos de interação com outros sites cabe verificar se os links para sites externos são acessíveis 
rapidamente, se complementam o texto principal sobre a doença e se são agradáveis. Assim a avaliação não deve se restringir ao site em questão, mas também deve verificar, ainda que sem muita profundidade, algumas características dos links relacionados que tratam da doença. A comunicação com os gestores do site representa um aspecto importante. A qualidade e finalidade das imagens sobre a doença completam este conjunto de critérios de usabilidade.

Quadro II. Indicadores de avaliação de Usabilidade de Site de Saúde

\begin{tabular}{|c|c|c|c|c|c|}
\hline Indicador & 10 pts & 5 pts & Zero & $\mathbf{P}$ & Total \\
\hline Existe um Menu Principal? & Sim & & Não & 3 & 30 \\
\hline O layout Geral do site é agradável? & Sim & + ou - & Não & 3 & 30 \\
\hline É rápido passar de uma página para outra? & Sim & As vezes & Não & 3 & 30 \\
\hline $\begin{array}{l}\text { Existem links externos que complementam } \\
\text { o texto que trata da Doença? }\end{array}$ & Sim & & Não & 2 & 20 \\
\hline Existe um Fale Conosco? & $\operatorname{Sim}$ & & Não & 2 & 20 \\
\hline $\begin{array}{l}\text { Existem meios de comunicação entre os } \\
\text { freqüentadores do site (Facebook/Twitter)? }\end{array}$ & Sim & & Não & 2 & 20 \\
\hline $\begin{array}{l}\text { Existem imagens na Página que trata da } \\
\text { Doença? }\end{array}$ & Sim & & Não & 2 & 20 \\
\hline Existem estatísticas de acesso ao site? & Sim & & Não & 2 & 20 \\
\hline Existem Menus secundários? & $\operatorname{Sim}$ & & Não & 1 & 10 \\
\hline Existe um Mapa do Site? & $\operatorname{Sim}$ & & Não & 1 & 10 \\
\hline $\begin{array}{l}\text { Existem mecanismos de busca interna no } \\
\text { site? }\end{array}$ & $\operatorname{Sim}$ & & Não & 1 & 10 \\
\hline Estes mecanismos são ágeis? & $\operatorname{Sim}$ & As vezes & Não & 1 & 10 \\
\hline Estes mecanismos ajudam na busca? & $\operatorname{Sim}$ & As vezes & Não & 1 & 10 \\
\hline $\begin{array}{l}\text { Os links externos complementam o texto } \\
\text { principal sobre a Doença? }\end{array}$ & $\operatorname{Sim}$ & As vezes & Não & 1 & 10 \\
\hline $\begin{array}{l}\text { Este links externos são acessíveis } \\
\text { facilmente? }\end{array}$ & $\operatorname{Sim}$ & As vezes & Não & 1 & 10 \\
\hline Este links externos são agradáveis? & Sim & As vezes & Não & 1 & 10 \\
\hline $\begin{array}{l}\text { É disponibilizado o endereço e telefone da } \\
\text { entidade que mantém o site? }\end{array}$ & Sim & & Não & 1 & 10 \\
\hline $\begin{array}{l}\text { As imagens que tratam da Doença têm } \\
\text { qualidade visual? }\end{array}$ & Sim & As vezes & Não & 1 & 10 \\
\hline $\begin{array}{l}\text { Estas imagens complementam o texto } \\
\text { escrito? }\end{array}$ & Sim & As vezes & Não & 1 & 10 \\
\hline Total & & & & & 300 \\
\hline
\end{tabular}

O terceiro critério se refere legibilidade do site, ou seja, ao grau de compreensão do que está escrito por parte do usuário. Assim não basta que a informação seja de qualidade, tenha acuidade e abrangência e esteja sendo apresentada de forma agradável e rápida. A Internet como um veículo de comunicação de massa, deve apresentar as informações de forma 
compreensível por leigos. É necessário que o leigo entenda o que está escrito no site. Em geral os autores preocupados com esta dimensão da avaliação utilizaram o Flesch-Kincaid Grade Level Score ${ }^{23}$. Trata-se de um software que classifica o grau de compreensão do texto segundo o número de sílabas por palavra e o número de palavras por frase. Há ainda quem utilize o Fry Readability Graph (FRG)[30]. Neste caso extraem-se 100 palavras e frases do início, meio e fim da amostra recolhida. Em seguida contam-se o número sílabas de cada palavra e frase selecionada. O FRG calcula e estima o nível de compreensão em função do número médio de sílabas nas frases e nas palavras utilizadas em cada avaliação. Os autores que utilizaram este recurso ${ }^{27}$ concluíram, por exemplo, que os textos presentes nos sites em espanhol tendem a ter mais sílabas do que os em inglês. A avaliação da legibilidade das informações em sites de saúde é o principal desafio para a proposta metodológica que este estudo apresenta. Eysenbach, e colaboradores ${ }^{23}$, depois de realizar ampla revisão sistemática em um número bastante significativo de artigos concluíram que nenhum dos estudos desenvolveu análises de legibilidade com consumidores de fato (actual consumers). Neste trabalho os consumidores de fato foram os autores deste artigo.

Em relação à legibilidade foram arrolados vinte e três indicadores. De posse da ferramenta apresentada nos quadro I, II e III foi feita a avaliação da qualidade da informação de saúde nos sites selecionados.

Os indicadores de legibilidade estão voltados para observar se o usuário do site entendeu ou não o que está escrito e se encontrou muitas frases ou palavras que não conhece, nos principais segmentos que compõem o site, a saber: a primeira página e os locais onde constam informações sobre o diagnóstico, prevenção, tratamento da doença. Neste artigo os indicadores construídos visavam avaliar a qualidade da informação em sites que abordassem uma doença contagiosa. Foi estabelecida uma hierarquia entre as informações disponíveis na primeira página e aquelas dispostas em outras áreas do site. Esta distinção se justifica na medida em que a primeira página desempenha um papel fundamental na atração ou repulsa do usuário em relação ao site. Se a impressão que o usuário tiver da primeira página for negativa, se a informação desejada não for encontrada ou se as frases forem longas e difíceis, com palavras e frases incompreensíveis, dificilmente ele continuará visitando aquele ambiente virtual. Por esta razão, os seis primeiros critérios receberam peso maior que os demais. Foi atribuído ainda o mesmo peso ao fato do usuário ter se sentido satisfeito com as informações disponíveis a ponto de recomendar este site à outra pessoa.

Quadro III. Indicadores de avaliação de Legibilidade de Site de Saúde

\begin{tabular}{|l|c|c|c|c|c|}
\hline Indicador & $\mathbf{1 0}$ ps & $\mathbf{5}$ ps & Zero & $\mathbf{P}$ & Total \\
\hline $\begin{array}{l}\text { Qual foi sua primeira impressão geral } \\
\text { do site? }\end{array}$ & Gostei & + ou - & Não Gostei & 2 & 20 \\
\hline $\begin{array}{l}\text { Você achou as frases muito longas e } \\
\text { difíceis na 1a. Página? }\end{array}$ & Não & $\begin{array}{c}\text { Um } \\
\text { pouco }\end{array}$ & Sim & 2 & 20 \\
\hline $\begin{array}{l}\text { Quantas frases você não entendeu } \\
\text { direito na 1a. Página? }\end{array}$ & 1 ou 2 & 3 ou 5 & Mais de 6 & 2 & 20 \\
\hline Você encontrou muitas palavras que & Não & Um & Sim & 2 & 20 \\
\hline
\end{tabular}




\begin{tabular}{|c|c|c|c|c|c|}
\hline Indicador & 10 ps & 5 ps & Zero & $\mathbf{P}$ & Total \\
\hline não conhecia na $1^{a}$. Página? & & pouco & & & \\
\hline $\begin{array}{l}\text { Quantas palavras você não entendeu } \\
\text { direito na } 1^{a} \text {. Página? }\end{array}$ & 1 ou 2 & 3 ou 5 & Mais de 6 & 2 & 20 \\
\hline $\begin{array}{l}\text { Assim que você abriu o site você } \\
\text { encontrou as informações que } \\
\text { procurava sobre a doença? }\end{array}$ & Sim & + ou - & Não & 2 & 20 \\
\hline $\begin{array}{l}\text { Você achou as frases muito longas no } \\
\text { texto que aborda o Diagnóstico da } \\
\text { Doença? }\end{array}$ & Não & $\begin{array}{l}\text { Um } \\
\text { pouco }\end{array}$ & Sim & 1 & 10 \\
\hline $\begin{array}{l}\text { Quantas frases sobre o Diagnóstico da } \\
\text { Doença você não entendeu direito? }\end{array}$ & 1 ou 2 & 3 ou 5 & Mais de 6 & 1 & 10 \\
\hline $\begin{array}{l}\text { Você encontrou muitas palavras que } \\
\text { não conhecia no texto que aborda o } \\
\text { Diagnóstico da Doença? }\end{array}$ & Não & $\begin{array}{c}\text { Um } \\
\text { pouco }\end{array}$ & Sim & 1 & 10 \\
\hline $\begin{array}{l}\text { Quantas palavras sobre o Diagnóstico } \\
\text { da Doença você não entendeu direito? }\end{array}$ & 1 ou 2 & 3 ou 5 & Mais de 6 & 1 & 10 \\
\hline $\begin{array}{l}\text { Você achou as frases muito longas no } \\
\text { texto que aborda a Prevenção da } \\
\text { Doença? }\end{array}$ & Não & $\begin{array}{c}\text { Um } \\
\text { pouco }\end{array}$ & Sim & 1 & 10 \\
\hline $\begin{array}{l}\text { Quantas frases sobre a Prevenção da } \\
\text { Doença você não entendeu direito? }\end{array}$ & 1 ou 2 & 3 ou 5 & Mais de 6 & 1 & 10 \\
\hline $\begin{array}{l}\text { Você encontrou muitas palavras que } \\
\text { não conhecia no texto que aborda a } \\
\text { Prevenção da Doença? }\end{array}$ & Não & $\begin{array}{c}\text { Um } \\
\text { pouco }\end{array}$ & Sim & 1 & 10 \\
\hline $\begin{array}{l}\text { Quantas palavras você não entendeu } \\
\text { direito no texto que aborda a } \\
\text { Prevenção da Doença? }\end{array}$ & 1 ou 2 & 3 ou 5 & Mais de 6 & 1 & 10 \\
\hline $\begin{array}{l}\text { Você achou as frases muito longas no } \\
\text { texto que aborda do Tratamento da } \\
\text { Doença? }\end{array}$ & Não & $\begin{array}{c}\text { As } \\
\text { vezes }\end{array}$ & Sim & 1 & 10 \\
\hline $\begin{array}{l}\text { Quantas frases sobre o Tratamento da } \\
\text { Doença você não entendeu direito? }\end{array}$ & 1 ou 2 & 3 ou 5 & Mais de 6 & 1 & 10 \\
\hline $\begin{array}{l}\text { Você encontrou muitas palavras que } \\
\text { não conhecia no texto que aborda o } \\
\text { Tratamento da Doença? }\end{array}$ & Não & $\begin{array}{c}\text { As } \\
\text { vezes }\end{array}$ & Sim & 1 & 10 \\
\hline Quantas palavras sobre o Tratamento & 1 ou 2 & 3 ou 5 & Mais de 6 & 1 & 10 \\
\hline
\end{tabular}




\begin{tabular}{|c|c|c|c|c|c|}
\hline Indicador & $10 \mathrm{ps}$ & 5 ps & Zero & $\mathbf{P}$ & Total \\
\hline \multicolumn{6}{|l|}{ da Doença você não entendeu direito? } \\
\hline $\begin{array}{l}\text { Você achou as frases muito longas no } \\
\text { texto que aborda as Conseqüências do } \\
\text { Tratamento da Doença? }\end{array}$ & Não & $\begin{array}{c}\text { As } \\
\text { vezes }\end{array}$ & Sim & 1 & 10 \\
\hline $\begin{array}{l}\text { Quantas frases sobre as } \\
\text { Conseqüências do Tratamento da } \\
\text { Doença você não entendeu direito? }\end{array}$ & 1 ou 2 & 3 ou 5 & Mais de 6 & 1 & 10 \\
\hline $\begin{array}{l}\text { Você encontrou muitas palavras que } \\
\text { não conhecia no texto que aborda as } \\
\text { Conseqüências do Tratamento da } \\
\text { Doença? }\end{array}$ & Não & $\begin{array}{c}\text { As } \\
\text { vezes }\end{array}$ & $\operatorname{Sim}$ & 1 & 10 \\
\hline $\begin{array}{l}\text { Quantas palavras sobre as } \\
\text { Conseqüências do Tratamento da } \\
\text { Doença você não entendeu direito? }\end{array}$ & 1 ou 2 & 3 ou 5 & Mais de 6 & 1 & 10 \\
\hline $\begin{array}{l}\text { Você recomendará este site a um } \\
\text { amigo? }\end{array}$ & $\operatorname{Sim}$ & Talvez & Não & 2 & 20 \\
\hline Total & & & & & 300 \\
\hline
\end{tabular}

Como pode ser observado, cada um dos três quadros é composto por um número diferente de indicadores que avaliam aspectos específicos dentro de cada um dos critérios. Cada indicador tem um valor e um peso relativo diferente, compondo um quadro bastante abrangente. A soma dos valores relativos de cada indicador totaliza trezentos pontos em cada um dos quadros. Os três quadros totalizam o mesmo número de pontos. Com isso a proposta metodológica de avaliação da qualidade da informação em sites de saúde apresentada neste artigo sugere que nenhum dos critérios deva ter mais importância que o outro.

Amparados nestes critérios e indicadores será apresentada, a seguir, a avaliação das informações sobre AIDS em sites de Organizações Não Governamentais (ONG) que defendem os direitos de Lésbicas, Gays, Bissexuais, Travestis e Transexuais (LGBT) de oito estados do Brasil. Assim este estudo tem a pretensão de analisar uma amostra ampla da realidade nacional de atuação da ONGs LGBTs em todo o território nacional.

\section{Resultados e Discussão}

As ONGs foram sendo construídas durante a segunda metade do século $X X$ em resposta a fragilidade ou quase inexistência de órgãos da sociedade civil e à centralidade que o Estado passou a ocupar, sobretudo na América Latina, nos anos 1950/1960[31]. Com o fim da Guerra Fria e a crise de Welfare State, a ação das ONG assumiu uma importância estratégica na preservação de direitos dos cidadãos[32]. As ONG são formadas por grupos de pessoas com graus de instrução, organização e interesses bastante diversificados[33]. 
No final da década de 1980, começaram a ser organizadas, na Europa e nos Estados Unidos, ONG de luta contra a Aids, pela defesa dos direitos dos soropositivos contendo um forte discurso da solidariedade[34],[35]. Inicialmente, os integrantes destas ONG eram em geral homossexuais masculinos, soropositivos, com nível de escolaridade superior, com alguma tradição de militância política em partidos de esquerda e no movimento gay[36]. Aos poucos este espaço foi passando a estar aberto aos profissionais do sexo, as travestis, as lésbicas, transexuais e a todos que se mostravam sensíveis às questões sociais, culturais e políticas suscitadas pela epidemia. Durante a década de 1990 foram sendo criadas ONG de luta contra a AIDS em todo o Brasil[37]. Em 1995 trinta e um grupos organizaram a "Associação Brasileira de Lésbicas, Gays, Bissexuais, Travestis e Transexuais" (ABGLT). Hoje a ABGLT é uma rede nacional de 237 organizações afiliadas.

Para a realização desta pesquisa foram selecionadas oito das mais proeminentes e tradicionais ONG ligadas a LGBT em diferentes oito regiões do Brasil. Com isso este estudo pretende comparar os resultados em diferentes realidades no Brasil. Com isso, este artigo pretende analisar uma amostra nacional abrangente. Na Região Sul, foram selecionadas a organização "SOMOS - Comunicação, Saúde e Sexualidade"[38] de Porto Alegre, Rio Grande do Sul (RG) e o "Grupo Dignidade"[39], fundado em 1992 em Curitiba(PR). Na Região Sudeste foram analisados os sites da "Cidadania, Orgulho, Respeito, Solidariedade e Amor" (CORSA)[40], fundada em São Paulo (SP) em 1995, do "Portal Gay de Minas" (MGM)[41], de Juiz de Fora (MG) fundado em 2000 e da "Associação Brasileira Interdisciplinar de AIDS" (ABIA[42])' do Rio de Janeiro (RJ). Na Região Centro Oeste, especialmente em Brasília (BR), foi avaliado o site do "ParouTudo"[43], idealizado em fevereiro de 2003. No Nordeste foi examinado o site do "Movimento Gay Leões do Norte"[44] (2001), de Recife (PE) e do "Grupo de Resistência Asa Branca"[45] que atua no Ceará (CE).

Apesar da AIDS não ser mais uma doença que incide exclusivamente sobre esta população[46], esperava-se que estes sites mantivessem esta comunidade informada e atualizada sobre a evolução da doença, dos exames diagnósticos e as possibilidades de tratamento.

As oito ONG estudadas foram selecionadas por representarem uma mostra do conjunto das associações LGBT existentes no país. Este estudo analisou os sites destas Organizações Não Governamentais (ONG) durante o mês de Janeiro de 2011. Foram utilizados nesta análise os indicadores de avaliação de conteúdo, usabilidade e legibilidade apresentados acima. Os sites das ONG foram dispostos nos quadros abaixo segundo as unidades da federação onde as organizações têm sede. Assim, foram obtidos os seguintes resultados em relação ao conteúdo das informações sobre AIDS:

Quadro IV. Indicadores de avaliação de conteúdo de Site de Saúde

\begin{tabular}{|l|c|c|c|c|c|c|c|c|}
\hline Indicador / ong & rs & $\mathbf{p r}$ & $\mathbf{s p}$ & $\mathbf{~ m g}$ & $\mathbf{r j}$ & $\mathbf{b r}$ & $\mathbf{p e}$ & $\mathbf{c e}$ \\
\hline Consta o responsável pelo Site/ONG? & 0 & 30 & 30 & 0 & 30 & 0 & 30 & 30 \\
\hline $\begin{array}{l}\text { Constam as Credenciais do } \\
\text { Responsável? }\end{array}$ & 0 & 0 & 30 & 0 & 30 & 0 & 30 & 0 \\
\hline Consta o Patrocinador/Parceiro do Site? & 30 & 30 & 0 & 0 & 0 & 30 & 30 & 30 \\
\hline
\end{tabular}




\begin{tabular}{|c|c|c|c|c|c|c|c|c|}
\hline Indicador / ong & rs & pr & sp & mg & rj & br & pe & ce \\
\hline Consta a data da Criação do Site? & 0 & 20 & 0 & 20 & 20 & 0 & 0 & 0 \\
\hline Consta a data da última atualização? & 10 & 0 & 0 & 0 & 20 & 0 & 0 & 0 \\
\hline $\begin{array}{l}\text { Quando foi feita última atualização? } \\
\text { Há... }\end{array}$ & 10 & 10 & 0 & 0 & 10 & 10 & 5 & 10 \\
\hline Consta o Público a que o site se dirige? & 10 & 10 & 10 & 10 & 10 & 10 & 10 & 10 \\
\hline $\begin{array}{l}\text { Consta Fonte de Informação na Página } \\
\text { que trata da Doença? }\end{array}$ & 0 & 0 & 0 & 0 & 0 & 0 & 0 & 0 \\
\hline $\begin{array}{l}\text { Que Tipo de Fonte de Informação foi } \\
\text { utilizada na Página que trata da } \\
\text { Doença?? }\end{array}$ & 0 & 0 & 0 & 0 & 0 & 0 & 0 & 0 \\
\hline $\begin{array}{l}\text { Consta como fazer o exame } \\
\text { Diagnóstico da Doença? }\end{array}$ & 0 & 0 & 0 & 0 & 10 & 0 & 0 & 0 \\
\hline $\begin{array}{l}\text { O exame Diagnóstico está de acordo } \\
\text { com a ciência? }\end{array}$ & 0 & 0 & 0 & 0 & 10 & 0 & 0 & 0 \\
\hline Consta como se Prevenir da Doença? & 10 & 0 & 0 & 10 & 10 & 0 & 0 & 10 \\
\hline $\begin{array}{l}\text { A prevenção está de acordo com a } \\
\text { ciência? }\end{array}$ & 10 & 0 & 0 & 10 & 10 & 0 & 0 & 10 \\
\hline O Tratamento é preconizado? & 0 & 0 & 0 & 0 & 0 & 0 & 0 & 0 \\
\hline $\begin{array}{l}\text { O Tratamento está de acordo com a } \\
\text { ciência? }\end{array}$ & 0 & 0 & 0 & 0 & 0 & 0 & 0 & 0 \\
\hline $\begin{array}{l}\text { Constam as conseqüências do } \\
\text { Tratamento? }\end{array}$ & 0 & 0 & 0 & 0 & 0 & 0 & 0 & 0 \\
\hline $\begin{array}{l}\text { As conseqüências estão de acordo com } \\
\text { a ciência? }\end{array}$ & 0 & 0 & 0 & 0 & 0 & 0 & 0 & 0 \\
\hline Constam anúncios? & 10 & 10 & 0 & 10 & 10 & 0 & 10 & 10 \\
\hline Constam anúncios de medicamentos? & 10 & 10 & 10 & 10 & 10 & 10 & 10 & 10 \\
\hline $\begin{array}{l}\text { Consta quando o médico deve ser } \\
\text { chamado? }\end{array}$ & 0 & 0 & 0 & 0 & 0 & 0 & 0 & 10 \\
\hline Total & 100 & 120 & 80 & 70 & 180 & 60 & 125 & 130 \\
\hline
\end{tabular}

Neste primeiro quadro um aspecto chama a atenção: apenas cinco dos oito sites analisados apresentam alguma informação sobre AIDS. Tratam-se das ONG do Rio Grande do Sul, Rio de Janeiro, Brasília, Ceará e Minas Gerais. A ênfase está situada na prevenção e no uso de preservativos. Apenas o site da ABIA, do Rio de Janeiro, aborda a questão do exame diagnóstico. Nenhum destes cinco sites trata da questão do tratamento e de suas 
conseqüências. Utilizando os recursos de busca interna há como identificar quando o médico deve ser chamado.

Os resultados relacionados ao conteúdo nos pareceram de certa forma surpreendentes. Nenhum dos sites avaliados apresenta qualquer informação sobre o tratamento e suas consequências. Apenas a organização carioca mencionou como fazer o diagnóstico enquanto a cearense foi a única que mencionou quando o médico deve ser chamado. Se considerarmos aprovado o site que obtivesse $50 \%$ ou mais das respostas esperadas, apenas a ONG carioca seria incluída nesta relação. Os resultados obtidos foram, portanto muito aquém do esperado. Uma explicação para este resultado talvez esteja associado ao fato das ONGs não quererem abordar a dimensão clínica da doença, reservando suas páginas para o entretenimento.

Em relação à avaliação da usabilidade compõem-se o seguinte quadro:

Quadro V. Indicadores de avaliação de Usabilidade de Site de Saúde

\begin{tabular}{|l|l|l|l|l|l|l|l|l|}
\hline Indicador/ ong & $\mathbf{r g}$ & $\mathbf{p r}$ & $\mathbf{s p}$ & $\mathbf{~ m g}$ & $\mathbf{r j}$ & $\mathbf{b r}$ & $\mathbf{p e}$ & $\mathbf{c e}$ \\
\hline Existe um Menu Principal? & 0 & 30 & 30 & 30 & 30 & 30 & 30 & 30 \\
\hline O layout do site é agradável? & 15 & 15 & 0 & 15 & 30 & 30 & 15 & 30 \\
\hline $\begin{array}{l}\text { É rápido passar de uma página } \\
\text { para outra? }\end{array}$ & 30 & 30 & 30 & 0 & 30 & 30 & 30 & 30 \\
\hline $\begin{array}{l}\text { Existem links externos que } \\
\text { complementam o texto que trata } \\
\text { da Doença? }\end{array}$ & 0 & 0 & 0 & 0 & 0 & 0 & 0 & 0 \\
\hline Existe um Fale Conosco? & 20 & 20 & 20 & 20 & 20 & 20 & 20 & 20 \\
\hline $\begin{array}{l}\text { Existem meios de comunicação } \\
\text { entre os freqüentadores do site } \\
\text { (Facebook / Twitter)? }\end{array}$ & 20 & 0 & 20 & 0 & 20 & 20 & 0 & 20 \\
\hline $\begin{array}{l}\text { Existem imagens na Página que } \\
\text { trata da Doença? }\end{array}$ & 0 & 0 & 0 & 0 & 0 & 0 & 0 & 0 \\
\hline $\begin{array}{l}\text { Existem estatísticas de acesso ao } \\
\text { site? }\end{array}$ & 20 & 0 & 0 & 0 & 0 & 0 & 0 & 20 \\
\hline $\begin{array}{l}\text { Existem Menus secundários? } \\
\text { Existe um Mapa do Site? }\end{array}$ & 0 & 10 & 10 & 10 & 10 & 10 & 0 & 10 \\
\hline $\begin{array}{l}\text { Existem mecanismos de busca } \\
\text { interna no site? }\end{array}$ & 10 & 10 & 10 & 10 & 10 & 10 & 0 & 10 \\
\hline Estes mecanismos são ágeis? & 10 & 10 & 10 & 10 & 10 & 10 & 0 & 10 \\
\hline $\begin{array}{l}\text { Estes mecanismos ajudam na } \\
\text { busca? }\end{array}$ & 10 & 10 & 10 & 10 & 10 & 10 & 0 & 10 \\
\hline Os links externos complementam & 0 & 0 & 0 & 0 & 0 & 0 & 0 & 0 \\
\hline
\end{tabular}




\begin{tabular}{|l|l|l|l|l|l|l|l|l|}
\hline Indicador/ ong & rg & pr & sp & $\mathbf{~ m g}$ & $\mathbf{r j}$ & $\mathbf{b r}$ & $\mathbf{p e}$ & $\mathbf{c e}$ \\
\hline o texto principal sobre a Doença? & & & & & & & & \\
\hline $\begin{array}{l}\text { Este links são acessíveis } \\
\text { facilmente? }\end{array}$ & 0 & 0 & 0 & 0 & 0 & 0 & 0 & 0 \\
\hline $\begin{array}{l}\text { Este links externos são } \\
\text { agradáveis? }\end{array}$ & 0 & 0 & 0 & 0 & 0 & 0 & 0 & 0 \\
\hline $\begin{array}{l}\text { É disponibilizado o endereço e } \\
\text { telefone da entidade que } \\
\text { mantém o site? }\end{array}$ & 10 & 10 & 0 & 0 & 10 & 0 & 10 & 10 \\
\hline $\begin{array}{l}\text { As imagens que tratam da } \\
\text { Doença têm qualidade visual? }\end{array}$ & 0 & 0 & 0 & 0 & 0 & 0 & 0 & 0 \\
\hline $\begin{array}{l}\text { Estas imagens complementam o } \\
\text { texto escrito? }\end{array}$ & 0 & 0 & 0 & 0 & 0 & 0 & 0 & 0 \\
\hline Total & 145 & 145 & 140 & 105 & 190 & 170 & 105 & 210 \\
\hline
\end{tabular}

Neste segundo quadro destaca-se o fato dos sites que contém informações sobre AIDS não apresentarem qualquer ilustração que facilite o entendimento sobre a doença. No site gaúcho as informações partem de uma emissão sonora, onde o visitante escolhe o tema que deseja ouvir. O brasiliense apresenta programas disponíveis do Youtube. Os sites mineiro, carioca e cearense procuram responder às perguntas que consideram mais freqüentes em um texto escrito. Em todos os casos não há nenhum link com sites externos que complementem as informações disponibilizadas. Se compararmos os resultados obtidos no quadro anterior que versava sobre o conteúdo a informação com este que aborda a usabilidade os resultados são bem mais satisfatórios. Três dos oito sites avaliados obtiveram mais de $50 \%$ das respostas satisfatórias. Destaque mais uma vez as imagens sobre a doença que não aparecem em nenhum dos sites avaliados. Mais uma vez a ênfase dada parece concentrar-se na dimensão lúdica da vida deste grupo com seus valores e objetos de consumo.

Em relação à avaliação da legibilidade compõem-se o seguinte quadro:

Quadro VI. Indicadores de avaliação de Legibilidade de Site de Saúde

\begin{tabular}{|l|c|c|c|c|c|c|c|c|}
\hline Indicador/ong & rg & pr & sp & $\mathbf{~ m g}$ & $\mathbf{r j}$ & $\mathbf{b r}$ & $\mathbf{p e}$ & $\mathbf{c e}$ \\
\hline $\begin{array}{l}\text { Qual foi sua primeira impressão geral } \\
\text { do site? }\end{array}$ & 10 & 10 & 0 & 10 & 20 & 20 & 10 & 20 \\
\hline $\begin{array}{l}\text { Você achou as frases muito longas e } \\
\text { difíceis na 1a. Página do site? }\end{array}$ & 20 & 20 & 20 & 20 & 20 & 20 & 20 & 20 \\
\hline $\begin{array}{l}\text { Quantas frases você não entendeu } \\
\text { direito na 1a. Página do site? }\end{array}$ & 20 & 20 & 20 & 20 & 20 & 20 & 20 & 20 \\
\hline $\begin{array}{l}\text { Você encontrou muitas palavras que } \\
\text { não conhecia na 1a. Página do site? }\end{array}$ & 20 & 20 & 20 & 20 & 20 & 20 & 20 & 20 \\
\hline
\end{tabular}




\begin{tabular}{|c|c|c|c|c|c|c|c|c|}
\hline Indicador/ong & $\mathbf{r g}$ & pr & sp & mg & $\mathbf{r j}$ & br & pe & ce \\
\hline $\begin{array}{l}\text { Quantas palavras você não entendeu } \\
\text { direito na } 1^{a} \text {.Página do site? }\end{array}$ & 20 & 20 & 20 & 20 & 20 & 20 & 20 & 20 \\
\hline $\begin{array}{l}\text { Assim que você abriu o site você } \\
\text { encontrou as informações que } \\
\text { procurava sobre a doença? }\end{array}$ & 0 & 0 & 0 & 0 & 20 & 0 & 0 & 20 \\
\hline $\begin{array}{l}\text { Você achou as frases muito longas no } \\
\text { texto que aborda o Diagnóstico da } \\
\text { Doença? }\end{array}$ & 0 & 0 & 0 & 0 & 5 & 0 & 0 & 10 \\
\hline $\begin{array}{l}\text { Quantas frases sobre o Diagnóstico da } \\
\text { Doença você não entendeu direito? }\end{array}$ & 0 & 0 & 0 & 0 & 5 & 0 & 0 & 10 \\
\hline $\begin{array}{l}\text { Você encontrou muitas palavras que } \\
\text { não conhecia no texto que trata do } \\
\text { Diagnóstico da Doença? }\end{array}$ & 0 & 0 & 0 & 0 & 5 & 0 & 0 & 10 \\
\hline $\begin{array}{l}\text { Quantas palavras sobre o Diagnóstico } \\
\text { da Doença você não entendeu direito? }\end{array}$ & 0 & 0 & 0 & 0 & 5 & 0 & 0 & 10 \\
\hline $\begin{array}{l}\text { Você achou as frases muito longas no } \\
\text { texto que aborda a Prevenção da } \\
\text { Doença? }\end{array}$ & 10 & 0 & 0 & 10 & 5 & 0 & 0 & 10 \\
\hline $\begin{array}{l}\text { Quantas frases sobre a Prevenção da } \\
\text { Doença você não entendeu direito? }\end{array}$ & 10 & 0 & 0 & 10 & 5 & 0 & 0 & 10 \\
\hline $\begin{array}{l}\text { Você encontrou muitas palavras que } \\
\text { não conhecia no texto que aborda a } \\
\text { Prevenção da Doença? }\end{array}$ & 10 & 0 & 0 & 10 & 5 & 0 & 0 & 10 \\
\hline $\begin{array}{l}\text { Quantas palavras você não entendeu } \\
\text { direito no texto que aborda a } \\
\text { Prevenção da Doença? }\end{array}$ & 10 & 0 & 0 & 10 & 5 & 0 & 0 & 10 \\
\hline $\begin{array}{l}\text { Você achou as frases muito longas } \\
\text { que aborda do Tratamento da } \\
\text { Doença? }\end{array}$ & 0 & 0 & 0 & 0 & 0 & 0 & 0 & 0 \\
\hline $\begin{array}{l}\text { Quantas frases sobre o Tratamento da } \\
\text { Doença você não entendeu direito? }\end{array}$ & 0 & 0 & 0 & 0 & 0 & 0 & 0 & 0 \\
\hline $\begin{array}{l}\text { Você encontrou muitas palavras que } \\
\text { não conhecia no texto que aborda o } \\
\text { Tratamento da Doença? }\end{array}$ & 0 & 0 & 0 & 0 & 0 & 0 & 0 & 0 \\
\hline $\begin{array}{l}\text { Quantas palavras sobre o Tratamento } \\
\text { da Doença você não entendeu direito? }\end{array}$ & 0 & 0 & 0 & 0 & 0 & 0 & 0 & 0 \\
\hline $\begin{array}{l}\text { Você achou as frases muito longas no } \\
\text { texto que aborda as Conseqüências } \\
\text { do Tratamento da Doença? }\end{array}$ & 0 & 0 & 0 & 0 & 0 & 0 & 0 & 0 \\
\hline $\begin{array}{l}\text { Quantas frases sobre as } \\
\text { Conseqüências do Tratamento da } \\
\text { Doença você não entendeu direito? }\end{array}$ & 0 & 0 & 0 & 0 & 0 & 0 & 0 & 0 \\
\hline
\end{tabular}




\begin{tabular}{|l|c|c|c|c|c|c|c|c|}
\hline Indicador/ong & rg & pr & sp & $\mathbf{~ m g}$ & rj & br & pe & ce \\
\hline $\begin{array}{l}\text { Você encontrou muitas palavras que } \\
\text { não conhecia no neste texto? }\end{array}$ & 0 & 0 & 0 & 0 & 0 & 0 & 0 & 0 \\
\hline $\begin{array}{l}\text { Quantas palavras sobre as } \\
\text { Conseqüências do Tratamento da } \\
\text { Doença você não entendeu direito? }\end{array}$ & 0 & 0 & 0 & 0 & 0 & 0 & 0 & 0 \\
\hline $\begin{array}{l}\text { Você recomendará este site a um } \\
\text { amigo? }\end{array}$ & 20 & 0 & 0 & 0 & 20 & 0 & 0 & 20 \\
\hline Total & 150 & 90 & 80 & 130 & 180 & 100 & 140 & 220 \\
\hline
\end{tabular}

Em todos os casos, o usuário tem dificuldade de encontrar as informações sobre AIDS. Nos sites gaúcho, fluminense e brasiliense elas estão nos links "Qual é a sua?" "Interação" e "Estruturação". Nos sites cearense e mineiro elas estão nos links "Saúde" e "Dicas de Saúde". O site do "Somos" do Rio Grande do Sul, as informações sobre a AIDS são disponibilizadas através de uma emissão sonora. Apesar de não ser um texto escrito, o texto sonoro é de fácil compreensão e muito bem feito. Os programas disponíveis no Youtube pelo site brasiliense apresentam temas específicos através de entrevistas com especialistas. Nos sites mineiro e cearense os textos são incompletos e superficiais e no carioca ele é longo e de difícil compreensão.

O quadro final, síntese deste trabalho é o seguinte:

Quadro VII. Síntese Geral

\begin{tabular}{|l|c|c|c|c|c|}
\hline ONG / UF/ Indicador & UF & CONT. & NAVE. & LEGI. & TOTAL \\
\hline $\begin{array}{l}\text { Grupo de Resistência Asa Branca (GRAB) } \\
\text { http://www.grab.org.br }\end{array}$ & CE & 130 & 210 & 220 & 560 \\
\hline $\begin{array}{l}\text { Associação Brasileira Interdisciplinar de AIDS } \\
\text { (ABIA) } \\
\text { http://www.abiaids.org.br }\end{array}$ & RJ & 180 & 190 & 180 & 550 \\
\hline $\begin{array}{l}\text { SOMOS - Comunicação, Saúde e Sexualidade } \\
\text { http://somosglbt.blogspot.com/ }\end{array}$ & RG & 100 & 145 & 150 & 395 \\
\hline $\begin{array}{l}\text { Movimento Gay Leões do Norte } \\
\text { http://www.leoesdonorte.org.br }\end{array}$ & PE & 125 & 105 & 140 & 370 \\
\hline $\begin{array}{l}\text { Grupo Dignidade } \\
\text { http://www.grupodignidade.org.br/blog/ }\end{array}$ & pr & 120 & 145 & 90 & 355 \\
\hline $\begin{array}{l}\text { ParouTudo } \\
\text { http://www.paroutudo.com }\end{array}$ & BR & 60 & 170 & 100 & 330 \\
\hline $\begin{array}{l}\text { Portal Gay de Minas (MGM) } \\
\text { http://www.mgm.org.br/portal/ }\end{array}$ & MG & 70 & 105 & 130 & 305 \\
\hline $\begin{array}{l}\text { Cidadania, Orgulho, Respeito, Solidariedade e } \\
\text { Amor (CORSA) http://corsa.wikidot.com/ }\end{array}$ & SP & 80 & 140 & 80 & 300 \\
\hline
\end{tabular}




\section{Conclusões}

Este artigo constatou que os sites mantidos por ONG de Gays, Lésbicas, Bissexuais e Transexuais do Brasil não dão destaque a divulgação de informações sobre AIDS. Dos oito sites analisados apenas cinco contém links onde o tema é abordado. Apesar dos sites avaliados não poderem ser propriamente considerados "de saúde" eles se dirigem a uma população profundamente afetada por esta epidemia. Alem disso, cabe mencionar que alguns deles recebem apoio do Ministério da Saúde, como consta nos sites das ONG do Paraná e de Pernambuco, ou ainda pelo Departamento de DST/Aids e Hepatites Virais do Ministério da Saúde como é o caso do "Grupo de Resistência Asa Branca" do Ceará.

Este trabalho combina três dimensões na avaliação das informações disponíveis em sites de saúde e apresenta os resultados segundo critérios e indicadores com seus respectivos pesos e valores. A metodologia proposta diante da confrontação empírica mostrou ser adequada. A limitação deste trabalho reside no fato da avaliação não ter sido feita pela população alvo das ONG e ter se limitado a oito sites.

Os resultados obtidos nesta investigação sugerem que é necessária uma melhoria da qualidade da informação sobre HIV nos sites avaliados. Esta talvez seja a realidade de outros sites que abordem outras patologias. Esta metodologia poderá ser aprimorada em futuros estudos e pesquisas, mas traz para agenda de discussão o tema da qualidade da informação tão caro para a promoção da saúde[47]. Este estudo demonstra que a avaliação da qualidade da informação na Internet é imprescindível.

Lopes (2012) avaliou recentemente as experiências internacionais voltadas para avaliação da qualidade da informação on line. Ela conclui seu trabalho afirmando que a literatura especializada internacional adverte sobre o perigo que a informação disponibilizada na Web pode oferecer aos internautas. Este foi uma das tarefas que este artigo procurou cumprir.

\section{Referências}

[1] LEVY, P. As Tecnologias têm um impacto? In: . Cibercultura. São Paulo: Ed. 34, 1999. p.21-31.

[2] GARBin, H. B. R.; PEREIRA NETO, A. F.; GUILAM, M. R. A internet, o paciente expert e a prática médica: uma análise bibliográfica. Interface, v. 12, n.26, p. 579-588, 2008.

[3] CASTELLS, M. Lições da História da Internet. In: - A Galáxia da Internet. Rio de Janeiro: Zahar, 2003. p. 13-33.

[4] BARBOSA, A. (Coord.) Pesquisa sobre o uso das tecnologias da informação e da comunicação no Brasil: TIC Domicílios e TIC Empresas 2009. São Paulo: Comitê Gestor da Internet no Brasil, 2010. p. 241.

[5] KORP, P. Health on the Internet: implications for health promotion. Health Education Research, v. 21, n.1, p.78-86, 2006.

[6] EDEJER, T. T. Disseminating health information in developing countries: the role of the Internet. British Medical Journal, 2000, v. 321, p.797-800. 
[7] PANDOLFINI, C.; IMPICCIATORE, P.; BONATI, M. Parents on the Web: risks for quality management of cough in children. Pediatrics., v.105, p.3, 2000.

[8] BRAGA, S. S.; FRANÇA, A. S.; NICOLÁS, M. A. Os partidos políticos brasileiros e a internet: uma avaliação dos websites dos partidos políticos do Brasil. Rev. Sociol. Polit., v.17, n.34, p.183-208, 2009.

[9] GHEDINE, T.; TESTA, M.; FREITAS, H. Educação a distância via Internet em grandes empresas brasileiras. Rev. adm. empres., v.48, n.4, p.49-63, 2008.

[10] LATTHE, P. M. et al. Quality of medical information about menorrhagia on the worldwide web. BJOG., v.107, p. 39-43, 2000.

[11] SANTOS, Vagner et al. Sites sobre drogas de abuso: recursos para avaliação. Trab. educ. saúde, v.8, n.3, p.575-585, nov. 2010.

[12] GONDIM, Ana P.; FALCÃO, Cláudio B. Avaliação das farmácias virtuais brasileiras. Rev. Saúde Pública, , v.41, n.2, p.297-300, abr. 2007.

[13] JULIANI, Carmen M. C. M.; KURCGANT, Paulina. Tecnologia educacional: avaliação de um web site sobre Escala de Pessoal de Enfermagem. Rev. esc. enferm. USP, v.43, n.3, p.512519, set. 2009.

[14] LEITE, Filipa ; CORREIA, André. Quality evaluation of websites with information on childhood dental caries in Portuguese language. Rev. odonto ciênc., v.26, n.2, p.116-120, 2011.

[15] SILVA, Flávia B.; CASSIANI, Silvia H. ; ZEM-MASCARENHAS, Silvia H. A Internet e a enfermagem: construção de um site sobre administração de medicamentos. Rev. Latino-Am. Enfermagem, v.9, n.1, p.116-122, jan. 2001.

[16] MARQUES, Isaac R. A; MARIN, Heimar. Enfermagem na WEB: o processo de criação e validação de um WEB site sobre doença arterial coronariana. Rev. Latino-Am. Enfermagem, v.10, n.3, p.298-307, jun. 2002.

[17] SILVA, Leonardo V. E. R.; MELLO JÚNIOR, João F.; MION, Olavo. Avaliação das informações sobre rinite alérgica em sites brasileiros na rede mundial de computadores (Internet). Rev. Bras. Otorrinolaringol., v.71, n5, p.590-597, out. 2005.

[18] BARBOSA, Andréa L. ; MARTINS, Elisabeth N. Evaluation of Internet websites about floaters and light flashes in patient education. Arq. Bras. Oftalmol., v.70, n.5, p.839-843, Oct. 2007.

[19] LINS, Thaís Honório; MARIN, Heimar de Fátima. Avaliação de website sobre assistência de enfermagem na sala de recuperação pós-anestésica. Acta paul. enferm., v.25, n.1, p.109-115, 2012.

[20] WYATT, J. C. Commentary: measuring quality and impact of the world wide web. BMJ, v. 314, p. $1879-1881,1997$. 
[21] IMPICCIATORE, P. et al. Reliability of health information for the public on the world wide web: systematic survey of advice on managing fever in children at home. BMJ, v. 314, p. 1875-1879, 1997.

[22] SILBERG, W. M. ; LUNDBERG, G.D.; MUSACCHIO, R. A. Assessing, controlling, and assuring the quality of medical information on the Internet. JAMA, v. 277, p. 1244-1245, 1997.

[23] EYSENBACH, G. et al. Empirical studies assessing the quality of health information for consumers on the world wide web: a systematic review. JAMA, v. 287, p. 2691-2700, 2002.

[24] RESOLUÇÃo no 097/2001 - Diário Oficial do Estado de São Paulo, São Paulo, 9 de março de 2001.

[25] FRASCA, D.; MALEZIEUX, R.; MERTENS, P.; NEIDHARDT, J. P. H.; VOIGLIO, E. J. Review and evaluation of anatomy sites on the Internet (updated 1999). Surg Radiol Anat., v. 22, p.107-110, 2000.

[26] SHON J, MUSEN, M. A. The low availability of metadata elements for evaluating the quality of medical information on the World Wide Web. Proc AMIA Symp, p.945-949, 1999.

[27] ROSSI, O. S.; BATISTA, N. A. O ensino da comunicação na graduação em medicina: uma abordagem. Interface, v. 10, n.19, p. 93-102, 2006.

[28] SILVINO, A. M. D.; ABRAHAO, J. I. Navegabilidade e inclusão digital: usabilidade e competência. RAE electron., v.2, n. 2, p. 1-17, 2003.

[29] GILLOIS, P. et al. A critical appraisal of the use of Internet for calculating cardiovascular risk. Proc AMIA Symp., p. 775-779, 1999.

[30] GRETCHEN, K.; BERLAND, M. N.; ELLIOTT, L. S. et al. Health Information on the Internet: accessibility, quality, and readability in english and spanish. JAMA, v. 285, n. 20, p. 2612-2621, 2001.

[31] SANCHEZ, M. R. Breves considerações sobre os mecanismos de participação para ONG na OMC. Sur, Rev. int. direitos human, v. 3, n. 4, p. 102-125, 2006.

[32] DOWBOR, L. Tendências da gestão social. Saude soc. 1999; v. 8, n.1, p. 3-16.

[33] PINTO, C. R. J. As ONG e a política no Brasil: presença de novos atores. Dados, v. 49, n.3, p. 651-670, 2006.

[34] ZAQUIEU, A. P. V. Os desafios da alteridade: considerações sobre gênero e sexualidade entre militantes de uma ONG/Aids carioca. Hist. cienc. saude-Manguinhos,v. 13, n. 1, p.33-54, 2006.

[35] CASTRO-SILVA, C. R.; HEWITT, W. E.; CAVICHIOLI, S. Igualdades e dessimetrias: a participação política em ONG HIV/AIDS do Canadá e do Brasil. Psicol. Soc., v.19, n.2, p.79-88, 2007.

[36] SILVA, C. L. C. ONG/Aids, intervenções sociais e novos laços de solidariedade social. Cad. Saúde Pública, v. 14, n. s2, p. 129-39, 1998. 
[37] CÂMARA, C.; LIMA R. M. Histórico das ONG/AIDS e sua contribuição no campo das lutas sociais. Cadernos ABONG, São Paulo, v.28, p.29-74, 2000.

[38] http://somosglbt.blogspot.com/

[39] http://www.grupodignidade.org.br/blog/

[40] http://corsa.wikidot.com/

[41] http://www.mgm.org.br/portal/

[42] http://www.abiaids.org.br

[43] http://www.paroutudo.com

[44] http://www.leoesdonorte.org.br

[45] http://www.grab.org.br

[46] MAIA, C.; GUILHEM, D.; FREITAS, D. Vulnerabilidade ao HIV/Aids de pessoas heterossexuais casadas ou em união estável. Rev. Saúde Pública. v.42, n.2, p. 242-248, 2008.

[47] GARBIN, H., GUILAM, M. C.; PEREIRA NETO, A. Internet na promoção da saúde: um instrumento para o desenvolvimento de habilidades pessoais e sociais. Physis, 2012, v.22, n.1, p.347-363.

Recebido:14.05.2012

Aceito:25.03.2013 